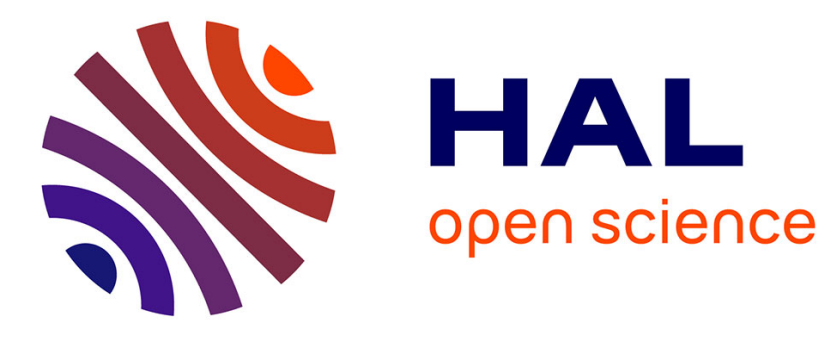

\title{
Spectroscopical study of \\ bacteriopurpurinimide-naphthalimide conjugates for fluorescent diagnostics and photodynamic therapy
}

Pavel A. Panchenko, Antonina N. Sergeeva, Olga A. Fedorova, Yuri V.

Fedorov, Roman I. Reshetnikov, Anastasiya E. Schelkunova, Michail A. Grin, Andrey F. Mironov, Gediminas Jonusauskas

\section{To cite this version:}

Pavel A. Panchenko, Antonina N. Sergeeva, Olga A. Fedorova, Yuri V. Fedorov, Roman I. Reshetnikov, et al.. Spectroscopical study of bacteriopurpurinimide-naphthalimide conjugates for fluorescent diagnostics and photodynamic therapy. Journal of Photochemistry and Photobiology B: Biology, 2014, 133, pp.140-144. 10.1016/j.jphotobiol.2014.03.008 . hal-00978356

\section{HAL Id: hal-00978356 https://hal.science/hal-00978356}

Submitted on 26 Feb 2015

HAL is a multi-disciplinary open access archive for the deposit and dissemination of scientific research documents, whether they are published or not. The documents may come from teaching and research institutions in France or abroad, or from public or private research centers.
L'archive ouverte pluridisciplinaire HAL, est destinée au dépôt et à la diffusion de documents scientifiques de niveau recherche, publiés ou non, émanant des établissements d'enseignement et de recherche français ou étrangers, des laboratoires publics ou privés.

\section{(ㄷ)(1) $\$$}

Distributed under a Creative Commons Attribution - NonCommerciall 4.0 International 


\title{
Spectroscopical study of bacteriopurpurinimide-naphthalimide conjugates for fluorescent diagnostics and photodynamic therapy
}

\author{
Pavel A. Panchenko a,*, Antonina N. Sergeeva ${ }^{a}$, Olga A. Fedorova ${ }^{a}$, Yuri V. Fedorov ${ }^{a}$, \\ Roman I. Reshetnikov ${ }^{\mathrm{b}}$, Anastasiya E. Schelkunova ${ }^{\mathrm{b}}$, Mikhail A. Grin ${ }^{\mathrm{b}}$, Andrey F. Mironov ${ }^{\mathrm{b}}$, \\ Gediminas Jonusauskas ${ }^{\mathrm{c}}$
}

\footnotetext{
${ }^{a}$ A.N. Nesmeyanov Institute of Organoelement Compounds of Russian Academy of Sciences (INEOS RAS), Vavilova str. 28, 119991 Moscow, Russia

${ }^{\mathrm{b}}$ Lomonosov Moscow State University of Fine Chemical Technologies, Vernadskogo pr. 86, 119571 Moscow, Russia

${ }^{\mathrm{c}}$ Laboratoire Ondes et Matière d'Aquitaine (LOMA), UMR CNRS 5798, Bordeaux 1 University, Cours de la Libération 351, 33405 Talence, France
}

* Corresponding author. Tel.: +7 49913580 98; fax: +7 49913550 85; E-mail address: pavel@ineos.ac.ru (P.A. Panchenko).

\begin{abstract}
A B S T R A C T
Two novel bis(chromophoric) dyads ABPI-NI1 and ABPI-NI2 containing 1,8-naphthalimide and bacterio-purpurinimide units linked by p-phenylenemethylene (ABPI-NI1) and pentamethylene (ABPI-NI2) spacers were prepared to test their ability to be used in the design of effective agents for both photody-namic therapy (PDT) and fluorescent tumor imaging. Photophysical studies revealed that the emission from the naphthalimide chromophore in both conjugates was partially quenched due to resonance energy transfer between the photoactive components. Compound ABPI-NI2 with more sterically flexible oligomethylene group demonstrated higher fluorescence intensity as compared with that for ABPI-NI1. @ 2014 Elsevier B.V. All rights reserved.
\end{abstract}

Keywords:

1,8-Naphthalimide; Bacteriopurpurinimide; Conjugate; Photodynamic therapy; Fluorescence imaging;

Resonance energy transfer; PM6 semiempirical calculations

\section{Introduction}

Cancer is known to be one of the deadliest diseases of our time and throughout the world. Current treatment modalities for patients afflicted by cancer include surgery, radiation therapy, chemotherapy, and a relatively novel option called photodynamic therapy $[1,2]$. Surgery is used to excise abnormal growths and surrounding tissue, but the procedure is invasive and may be complicated by relapse of the cancer if not all of the tumor cells are removed. Chemotherapy employs different cytotoxic chemicals to attack or block specific cellular and molecular mechanisms that aid tumor growth. Unfortunately, patients on chemotherapeutics suffer from side effects due to adverse drug toxicities. Radiation uses ionizing energy to attack neoplastic cells, but it is nonspecific and may cause damage to surrounding healthy tissue, which can lead to the occurrence of secondary cancers. PDT uses a drug known as a photosensitizer, light, and oxygen to destroy tumors and their surrounding vasculature. PDT has several advantages in that (i) there is no systemic, organ, or tissue toxicity, (ii) it is noninvasive, and (iii) it can be used repeatedly as a primary or adjuvant treatment $[3,4]$.
Porphyrin-based photosensitizing agents for PDT possess unique advantages due to their ability to be retained in tumors and to produce cytotoxic singlet oxygen upon exposure to an appropriate wavelength of light. UV/Vis absorption spectra of porphyrins contains strong $\pi-\pi^{*}$ transition around $400 \mathrm{~nm}$ (Soret band) and satellite Q-bands in the visible region between 600 and $800 \mathrm{~nm}$, which coincidently drop into "therapeutic window" where tissues exhibit the best light penetration ability [2]. Therefore only Q-bands are useful for PDT. To date, many porphyrins have been obtained to test their efficiency in PDT and some of them are currently at different stages of clinical or preclinical trials [5-9].

In addition to therapy, the difference in concentration of the photosensitizer in malignant and normal tissue could be the basis of fluorescent imaging. Noninvasive in nature, fluorescent imaging instruments are simple and not expensive to operate and can allow precise assessment of the location and size of a tumor, providing information on its invasiveness in adjacent tissue [10,11]. Unfortunately, porphyrins and most of the tumor-avid long-wavelength photosensitizers (e.g. chlorins and bacteriochlorins) have very small wavelength differences between their NIR absorption and emission bands (Stokes shifts). Such an inherent property limits application of these molecules for imaging. To overcome this difficulty a new approach have been recently developed by Pandey 

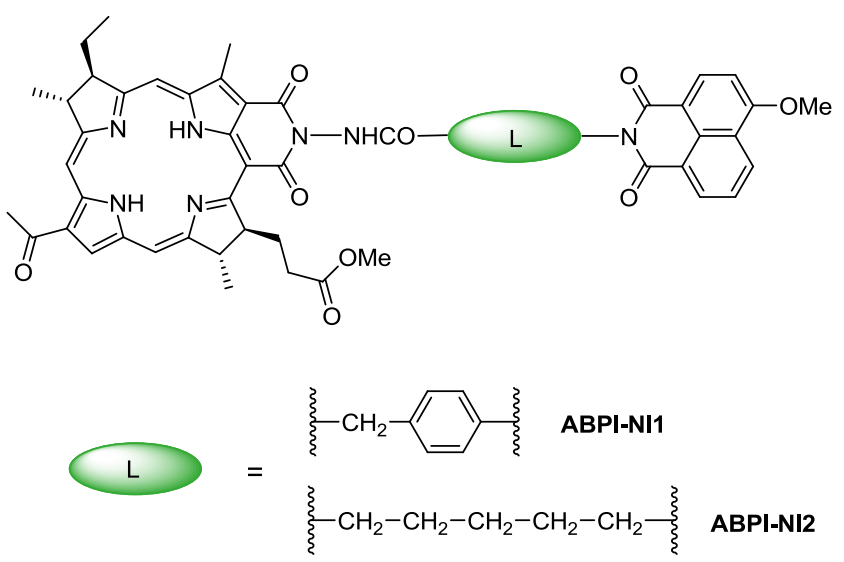

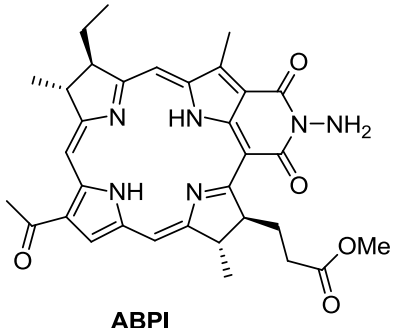<smiles>[R]N1C(=O)c2cccc3c(OC)ccc(c23)C1=O</smiles>

NI1 $\left(\mathrm{R}=p-\mathrm{C}_{6} \mathrm{H}_{4} \mathrm{CH}_{2} \mathrm{COOH}\right)$

$\mathrm{N} / 2\left(\mathrm{R}=\left(\mathrm{CH}_{2}\right)_{5} \mathrm{COOH}\right)$

Scheme 1.

and co-workers [12,13], who offered the construction of tumorspecific imaging agents by conjugating of organic fluorophores with appropriate photophysical properties to porphyrin-based compounds. Thus, the excitation of the labeled fluorescent species is expected to produce the strong emission signal, which could be used to monitor tumor responses to treatment. Further excitation by an other light wavelength corresponding to the absorption maxima of porphyrin leads to formation of singlet oxygen responsible for cancer cell damage.

The work discussed herein describes the study of spectral properties of novel dyad compounds ABPI-NI1 and ABPI-NI2 (Scheme 1) bearing $N$-aminobacteriopurpurinimide (ABPI) and naphthalimide (NI) chromophores aimed to determine their ability to be used in the design of effective agents for both PDT and tumor imaging. Bacteriopurpurinimide type photosensitizer was chosen since the presence of fused imide cycle in the macrocyclic system is known to enhance pigment stability and result in the red shift of longwavelength $\mathrm{Q}_{\mathrm{y}}$-band in the absorption spectrum compared to chlorins and bacteriochlorins [14]. Yet, in spite of their promising optical properties ABPI and its derivatives exhibit high light-induced cytotoxicity on A-549 human adenocarcinoma cells [15]. As a basic fluorophore responded for the imaging effect we used 1,8-naphthalimide. Due to strong emission in the visible region, large Stokes shifts and excellent photostability compounds of this type are considered to be good candidates for the construction of fluorescent probes [16,17], organic electroluminescent devices [18], laser dyes [19] and optical brighteners [20]. Moreover, the utility of naphthalimides as fluorescent markers in cells has also been demonstrated [21,22].

\section{Materials and methods}

\subsection{Synthesis of the compounds}

For the synthesis of conjugates ABPI-NI1 and ABPI-NI2, Naminobacteriopurpurinimide ABPI was prepared from Bacteriochlorophyll $a$ by following the literature procedure [23,24], which was afforded from the frozen biomass containing Rhodobacter Capsulatus. Reaction of ABPI with acyl chlorides derived from NI1 and NI2 gave the target compounds. The experimental details concerning the synthesis of ABPI-NI1, ABPI-NI2 and naphthalimides NI1 and NI2 are described in Supplementary Information data file.

\subsection{Steady-state and time-resolved optical measurements}

The absorption spectra were taken on a Varian-Cary 5G spectrophotometer. The fluorescence quantum yield measurements were performed using a Varian-Cary 5G spectrophotometer and a
FluoroMax-3 spectrofluorimeter. Spectral measurements were carried out in air-saturated solutions at $20 \pm 1^{\circ} \mathrm{C}$. Acetonitrile (Aldrich) and dimethylsulfoxide (Spectro) of spectrophotometric grade were used. The concentrations of studied compounds were of about $0.5-1.0 \times 10^{-5} \mathrm{M}$. All measured fluorescence spectra were corrected for the nonuniformity of detector spectral sensitivity. Quinine sulfate in $1 \mathrm{~N} \mathrm{H}_{2} \mathrm{SO}_{4}\left(\varphi^{f l}=0.55\right)$ [25] and Coumarin 481 in acetonitrile $\left(\varphi^{f l}=0.08\right)$ [26] were used as a reference for the fluorescence quantum yield measurements. Fluorescence lifetimes were determined according to the method described earlier [27].

\subsection{Computational details}

The three dimentional structures of conjugates ABPI-NI1 and ABPI-NI2 were built with MOPAC program package using PM6 semiempirical method [28]. The calculations were performed at optimized geometries, which reached gradient variations less than $0.01 \mathrm{kcal} / \mathrm{mol}$. The solvent effect was included in geometry optimizations following the "COnductorlike Screening Model» (COSMO) implemented in MOPAC. A dielectric constant of $\varepsilon=40$ and a refraction index of solvent $(n)$ such that $n^{2}=2$ were used.

\section{Results and discussion}

The conjugates of bacteriopurpurinimide derivatives with the fluorescent dyes, in which the linker groups separate two photoactive components, can be considered as bis(chromophoric) systems, where the optical characteristics of the individual chromophores might be pertrubed to some extent as a result of mutual energy/ electron transfer process or exciplex formation originating from the feasible stereoelectronic properties of the excited state. Regarding the application of conjugates in PDT, one could reveal that the occurrence of such additional deactivation pathways, non-radiative in nature, would impair singlet oxygen sensitization or, alternatively, quench the emission of the fluorophore dye.

In order to avoid the decrease in emission efficiency of naphthalimide unit in the designed conjugates caused by fluorescence resonance energy transfer (FRET) to bacteriopurpurinimide, we followed the rule, according to which the FRET-process could occur whenever the emission spectrum of a donor fluorophore (naphthalimide) overlaps with the absorption spectrum of acceptor (ABPI) [29]. As it can be seen from Fig. 1, the absorption sectrum of ABPI in acetonitrile contains the interval between 440 and $520 \mathrm{~nm}$, where the absorption values are relatively low. At the same time, it is well-known that photophysical properties of 1,8-naphthalimides are strongly dependent on the nature of the substituent at C-4 involved in the charge transfer interaction with carboximide moiety and, in general, the derivatives with alkoxy 


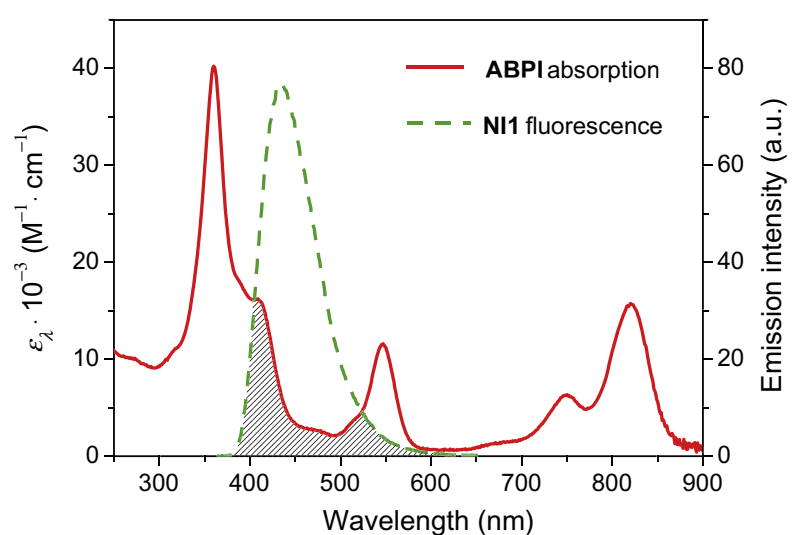

Fig. 1. Overlap between the ABPI absorption and NI1 fluorescence spectrum in acetonitrile.

groups exhibit blue fluorescence in the region of $430-470 \mathrm{~nm}$ [30-31]. Indeed, the low overlapping of methoxynaphthalimide NI1 emission band with APBI absorption was observed (Fig. 1) implying good fluorescent characteristics for conjugate ABPI-NI1.

Contrary to our expectations, we found that ABPI-NI1 showed very low fluorescence signal at $437 \mathrm{~nm}$ compared with the reference compound NI1 (Fig. 2b) and 85-fold reduction in the quantum yield $\left(\varphi^{f l}\right.$ for NI1 and APBI-NI1 in MeCN are 0.58 and 0.0068 respectively, Table 1). Such difference in $\varphi^{f l}$ values could be accounted for the fact that excitation light (with wavelength $360 \mathrm{~nm}$ ) used by us to collect the emission spectra is absorbed by both chromophores in ABPI-NI1 (see Fig. 2a for the comparison of absorption of ABPI-NI1 and NI1 at $360 \mathrm{~nm}$ ) and thus, less amount of excitation energy is consumed to produce the emission of naphthalimide fragment. To estimate the magnitude of this effect we compared the fluorescence quantum yields for the solution of ABPI-NI1 and the solution containing equimolar mixture of ABPI and NI1 (Table 1), and it was found that $\varphi^{f l}$ value for the mixture of chromophores (0.17) is 25 times higher compared to the value observed for ABPI-NI1 (0.0068). This result indicates that emission of naphthalimide in the conjugate ABPI-NI1 is quenched by a kind of non-radiative process which competes fairly well with the fluorescence in the excited state.

To clarify our assumption whether FRET is a reason of quenching of naphthalimide emission in ABPI-NI1, we calculated the rate constant $k_{F R E T}$ for FRET deactivation pathway on the basis of Förster resonance theory [29]. In this treatment $k_{F R E T}$ is given by Eq. (1):

$k_{\text {FRET }}=\frac{1}{\tau_{D}}\left(\frac{R_{0}}{r}\right)^{6}$

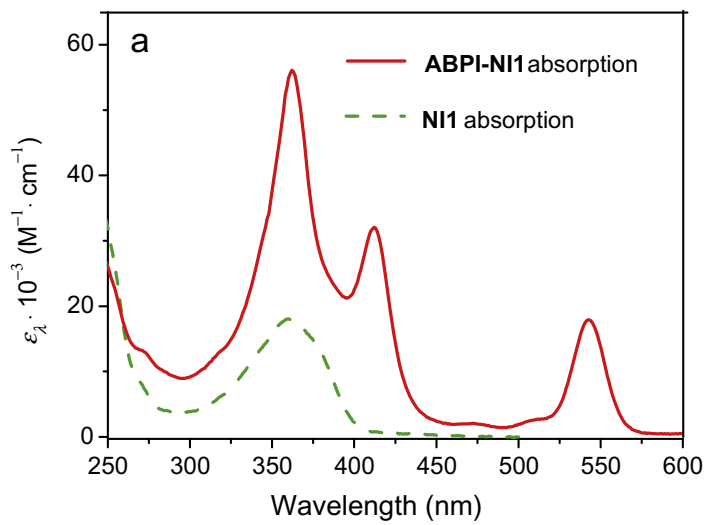

where $\tau_{D}$ is the excited state lifetime of the donor chromophore (naphthalimide) in the absence of acceptor (bacteriopurpurinimide) and $r$ is the donor-acceptor separation. As a parameter $\tau_{D}$ we used the fluorescence lifetime of compound NI1 in $\mathrm{MeCN}\left(\tau_{D}=7.5 \mathrm{~ns}\right)$. The distance between donor and acceptor chromophores $(r=13.0 \AA)$ was found from the PM6 optimized ground state geometry of ABPI-NI1 (see Fig. 3a). $R_{0}$ is a distance calculated according to the Eq. (2):

$R_{0}^{6}=\frac{9000 \ln 10 \kappa^{2} \varphi_{D}^{f l}}{128 \pi^{2} N_{A} n^{4}} \int_{0}^{\infty} F_{D}(\lambda) \varepsilon_{A}(\lambda) \lambda^{4} d \lambda$

where $\kappa^{2}$ is a factor which describes the relative orientations of the donor and acceptor, $\varphi_{D}^{f l}$ is the donor emission quantum yield in the absence of the acceptor, $n$ is the refractive index of the medium, $N_{A}$ is Avogadro constant $\left(N_{A}=6.02 \times 10^{23} \mathrm{~mol}^{-1}\right)$ and the integral defines the amount of overlap between the normalized emission spectrum of the donor $F_{D}(\lambda)$ and the acceptor absorption spectrum $\varepsilon_{A}(\lambda)$. In terms of Förster resonance theory, $R_{0}$ corresponds to the donoracceptor distance at which $50 \%$ of the excited donors undergo energy transfer to an acceptor and is usually known as the critical distance. Values of $R_{0}$ are typically $50-100 \AA$ when the transitions in both donor and acceptor are allowed and there is good overlap between the donor emission and acceptor absorption spectra [29]. Assuming that $\kappa^{2}=2 / 3$ (for a random orientation) and $\varphi_{D}^{f l}=0.58$ (the quantum yield of NI1 in $\mathrm{MeCN}$ ) we found the rate constant $k_{\text {FRET }}$ to be as high as $7.1 \times 10^{10} \mathrm{~s}^{-1}$, with the distance $R_{0}$ being $37.1 \AA$ (Table 1). On the other hand, the relaxation rate of donor naphthalimide chromophore in the absence of the acceptor can be well estimated by the sum of radiative $\left(k_{r}\right)$ and non-radiative $\left(k_{n r}\right)$ constants describing the excitation energy loss in the compound NI1, which is derived from the known fluorescence lifetime of NI1 as given in Eq. (3):

$k_{r}+k_{n r}=\frac{1}{\tau_{D}}=\frac{1}{7.5 \times 10^{-9} \mathrm{~s}}=1.3 \times 10^{8} \mathrm{~s}^{-1}$

The performed calculations reveal that the resonance energy transfer rate for the conjugate ABPI-NI1 could be higher compared with the emission rate at least by 2 orders of magnitude, and this could be the reason of fluorescence quenching. Apparently, the high $k_{F R E T}$ value is a result of a rather short distance between naphthalimide and ABPI chromophores $(r=13.0 \AA)$ lying within the range $0<r<0.5 R_{0}(18.5 \AA)$, where transfer efficiency $(E)$ is usually close to $100 \%$ [29]. As it can be seen from Table 1, transfer efficiencies $E$ for ABPI-NI1 obtained from theoretical calculations and steady-state fluorescence measurements are both higher than $95 \%$.

To avoid the decrease of naphthalimide fluorescence due to FRET to ABPI fragment we modified the structure of linker by using less rigid pentamethylene chain instead of $p$-phenylene-methylene

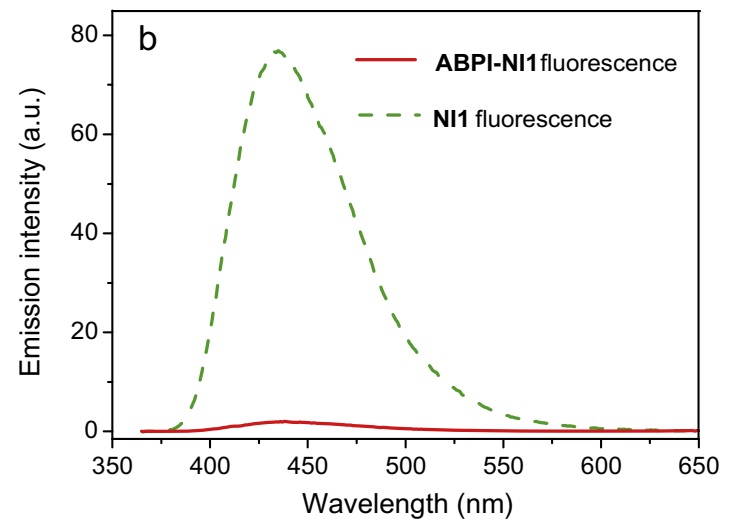

Fig. 2. Absorption (a) and fluorescence (b) spectra of conjugate ABPI-NI1 and naphthalimide NI1 in acetonitrile. Concentrations of compounds are both $5.8 \times 10^{-6} \mathrm{M}$. 

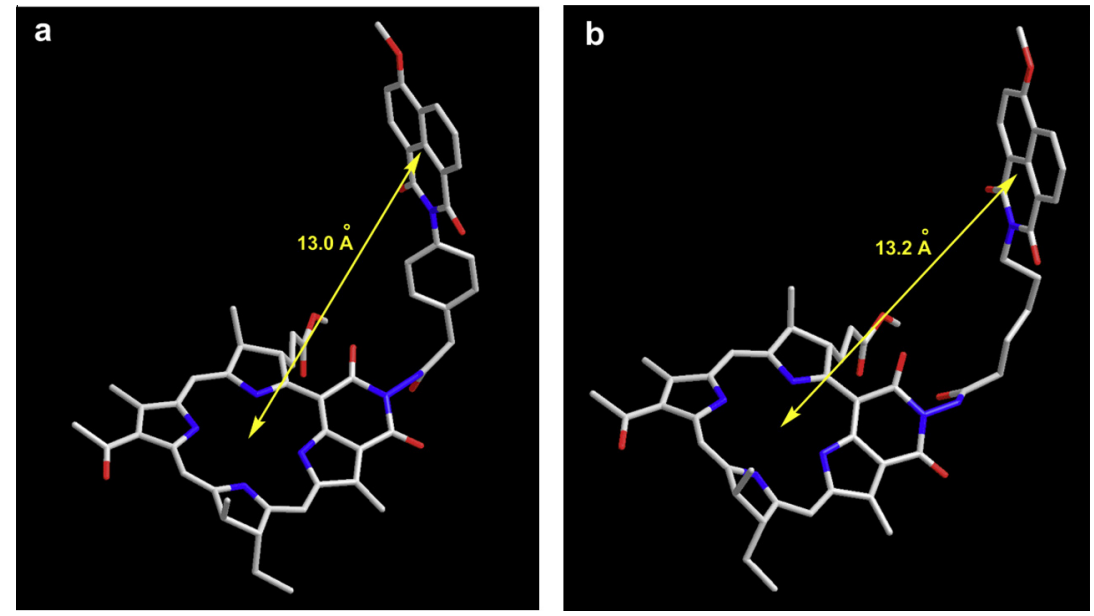

Fig. 3. PM6 optimized ground state geometry of the compounds ABPI-NI1 (a) and ABPI-NI2 (b).

group. This idea was realized in the conjugate ABPI-NI2. In this case, the molecule is expected to be more sterically flexible resulting in a more easy achievement of a conformation with nearly orthogonal orientation of dipole transition moments of chromophores at which energy transfer rate is close to zero. Although there are a large variety of conformers for ABPI-NI2, there could be some conformers where the FRET is hampered, and thus fluorescent characteristics could be improved to some extent with respect to ABPINI1. As it has been shown by Pandey and coworkers who conducted molecular modeling and photophysical studies for conjugates of purpurinimide with cyanine dyes, the increase of the number of relative orientations of two chromophores on going to a molecule with more flexible linker provides the better fluorescence imaging capabilities [13]. Following this design logic, we used the linker with almost same length as in the case of ABPI-NI1 (the distance between NI and ABPI fragments in ABPI-NI2 is $13.2 \AA$, see Fig. 3b), but with increased sterical flexibility. We did not further extend the oligomethylene chain in ABPI-NI2, because at a very high number of $\mathrm{CH}_{2}$ groups (higher than 5) the molecule could adopt a conformation where the ABPI and NI moieties are arranged as a small $\mathrm{H}$-aggregate stabilized by $\pi$-stacking interaction, in which the formation of non-emissive excimer state could be suggested. It should be noted that the quenching of naphthalimide fluorescence in excimers or exciplexes with $\pi$-donor aromatic compounds has been reported in literature [32-33].

The fluorescence quantum yields of ABPI-NI2, NI2 and equimolar mixture of ABPI and NI2 are presented in Table 1, the absorption and emission spectra displayed in Fig. S2 (Supplementary information). As the comparison of $\varphi^{f l}$ values shows, the emission intensity of naphthalimide is only 2 times quenched when going from the mixture ABPI + NI2 to ABPI-NI2 solution, which corresponds to $50.0 \%$ efficiency of FRET against $96.0 \%$ in the conjugate ABPI-NI1. Considering the observation that the overlap integral (3.30 $\times 10^{14} \mathrm{M}^{-1} \mathrm{~cm}^{-1} \mathrm{~nm}^{4}$, Table 1) and distance between the chromophores ( $r=13.2 \AA$ ) for ABPI-NI2, as well as the measured fluorescence quantum yield and lifetime of NI2 $\left(\varphi_{D}^{f l}=0.56\right.$, $\tau_{D}=6.7 \mathrm{~ns}$ ) which are very close to the corresponding parameters of ABPI-NI1 and NI1, one can see that the inhibition of FRET process in ABPI-NI2 could be only a result of conformational changes leading to the different relative orientation of chromophores with the orientation factor $\kappa^{2}$ (Eq. (2)) decreased to some extent. The high theoretical efficiency of energy transfer for ABPI-NI2 (Table 1) which does not agree with the experimental data could be explained by the choice of the same of $\kappa^{2}$ value (2/3) used by us for the calculation of rate constant $k_{F R E T}$ and Förster distance $R_{0}$ as in the case of ABPI-NI1. Obviously, the steric structure of studied conjugates is different and cannot be described within the same orientation of donor and acceptor chromophores. Because of size of molecules and their complex structure, we did not carry out the detailed quantum chemical calculations to explore the conformation flexibility of these conjugates and to estimate the factor $\kappa^{2}$ in each case, however, the performed results clearly indicate that these are steric reasons that respond for the different fluorescent characteristics of compounds ABPI-NI1 and ABPI-NI2.

Table 1

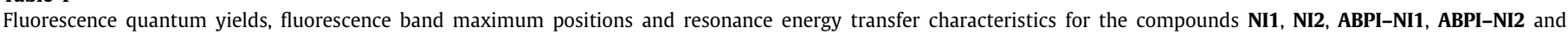
equimolar mixtures of ABPI + NI1 and ABPI + NI2.

\begin{tabular}{|c|c|c|c|c|c|c|c|}
\hline & \multirow[t]{2}{*}{$\varphi^{f l}$} & \multirow[t]{2}{*}{$\lambda_{\max }^{f l}(\mathrm{~nm})$} & \multirow[t]{2}{*}{$R_{0}(\AA)$} & \multirow[t]{2}{*}{ Overlap integral $\left(\mathrm{M}^{-1} \mathrm{~m}^{-1} \mathrm{~nm}^{4}\right)^{\mathrm{b}}$} & \multirow[t]{2}{*}{$k_{F R E T}\left(\mathrm{~s}^{-1}\right)$} & \multicolumn{2}{|l|}{$E(\%)$} \\
\hline & & & & & & Theory $^{\mathrm{c}}$ & Experiment $^{\mathrm{d}}$ \\
\hline NI1 & 0.58 & 434 & - & - & - & - & - \\
\hline $\mathrm{ABPI}+\mathrm{NI} 1$ & 0.17 & 436 & - & - & - & - & - \\
\hline ABPI-NI1 & 0.0068 & 436 & 37.1 & $2.49 \times 10^{14}$ & $7.1 \times 10^{10}$ & 99.8 & 96.0 \\
\hline NI2 & 0.56 & 446 & - & - & - & - & - \\
\hline $\mathrm{ABPI}+\mathrm{NI} 2$ & 0.11 & 448 & - & - & - & - & - \\
\hline ABPI-NI2 & 0.055 & 448 & 36.3 & $3.30 \times 1014$ & $6.4 \times 10^{10}$ & 99.8 & 50.0 \\
\hline
\end{tabular}

a The data for ABPI-NI1, NI1 and ABPI + NI1 were obtained using acetonitrile as a solvent and 360 nm excitation light $\left(\lambda_{\text {ex }}\right)$, the data for ABPI-NI2, NI2 and ABPI + NI2 using dimethylsulfoxide and $\lambda_{\mathrm{ex}}=340 \mathrm{~nm}$.

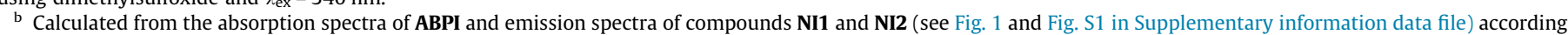
to Eq. (2).

c Calculated as $R_{0}^{6} /\left(R_{0}^{6}+r^{6}\right)$ [29], where $R_{0}$ is a critical Förster distance and $r$ is the distance between donor (NI) and acceptor (ABPI) chromophores.

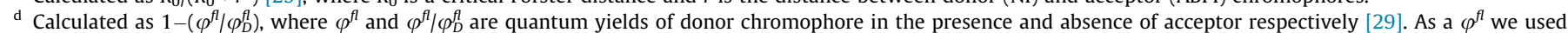

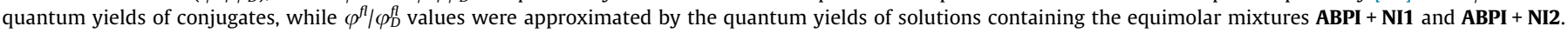




\section{Conclusions}

In summary, we have prepared two bacteriopupurinimidenaphthalimide dye conjugates ABPI-NI1 and ABPI-NI2. Evaluation of spectral properties has shown that the fluorescence intensity of naphthalimide residue is decreased with respect to compounds NI1 and NI2, which can be rationalized in terms of FRET interaction occurring from the fluorophore (NI) to photosensitizer (ABPI). The magnitude of the quenching effect is strongly dependent on the structure of the linker group. Upon the excitation at the absorption maxima of naphthalimide, compound ABPI-NI2 with more sterically flexible pentamethylene group exhibited higher emission intensity compared with that for ABPI-NI1 containing p-phenylene-methylene linker unit. Thus, through the studied molecules, conjugate ABPI-NI2 seems to be the better candidate for the application as a photosensitizing and imaging agent.

Our study illustrates a new approach for targeting highly emissive fluorophores to tumors, which is of great importance for simultaneous cancer diagnosis and therapy. The bifunctional conjugates provide an opportunity to independently select and associate appropriate photosensitizers and fluorophores. Our future work in this field will continue investigating the applicability of naphthalimide derivatives as signaling components in such systems. Due to facilely modified spectral characteristics, emission maxima of 1,8-naphthalimides can be shifted close to NIR region $[22,34]$ where the fluorescent contrast agents can provide planar and tomographic images at millimeter to centimeter depth, with millimeter to sub-millimeter resolution and very high sensitivity. Related research is currently in progress.

\section{Acknowledgements}

The work was supported by RFBR programs Nos. 13-03-00577 and 14-03-31935, program of Russian Ministry of Education and Science No. 8533 and CNRS-RAS exchange programs. Gediminas Jonusauskas thanks the Région Aquitaine for financial support.

\section{Appendix A. Supplementary material}

Supplementary data associated with this article can be found, in the online version, at http://dx.doi.org/10.1016/j.jphotobiol. 2014.03.008.

\section{References}

[1] R. Bonnet, Photosensitizers of the porphyrin and phthalocyanine series for photodynamic therapy, Chem. Soc. Rev. 24 (1995) 19-33.

[2] M. Ethirajan, Y. Chen, P. Joshi, R.K. Pandey, The role of porphyrin chemistry in tumor imaging and photodynamic therapy, Chem. Soc. Rev. 40 (2011) 340362.

[3] B.W. Henderson, T.J. Dougherty, How does photodynamic therapy work?, Photochem Photobiol. 55 (1992) 145-147.

[4] I. Macdonald, T.J. Dougherty, Basic principles of photodynamic therapy, J. Porphyrins Phtalocyanines 5 (2001) 2001-2011.

[5] D.A. Belnier, W.R. Greco, G.M. Loewen, V. Nava, A.O. Oseroff, R.K. Pandey, T. Tsuchida, T.J. Dougherty, Population pharmacokinetics of the photodynamic agent HPPH in cancer patients, Cancer Res. 63 (2003) 1806-1813.

[6] N.E. Martin, S.M. Hahn, Interstitial photodynamic therapy for prostate cancer: a developing modality, Photodiagn. Photodyn. Ther. (2004) 123-136.

[7] Y. Chen, G. Li, R.K. Pandey, Synthesis of bacteriochlorins and their potential utility in photodynamic therapy (PDT), Curr. Org. Chem. 8 (2004) 1105-1134.

[8] J.D. Miller, E.D. Baron, H. Scull, A. Hsia, J.C. Berlin, T. McCormick, V. Colussi, M.E. Kenny, K.D. Cooper, N.L. Olienick, Photodynamic therapy with the phthalocyanine photosensitizer Pc 4: the case experience with preclinical mechanistic and early clinical translational studies, Toxicol. Appl. Pharmacol. 224 (2007) 290-299.

[9] R.A. Weersink, A. Bogaards, M. Gertner, S.R.H. Davidson, K. Zhang, G. Netchev, T. Trachterberg, B.C. Wilson, Techniques for delivery and monitoring of
TOOKAD (WST09)-mediated photodynamic therapy of the prostate: clinical experience and practicalities, J. Photochem. Photobiol. B 79 (2005) 211-222.

[10] P.K. Pandey, N. James, Y. Chen, M.P. Dobhal, Cyanine dye based compounds for tumor imaging with and without photodynamic therapy, Top. Heterocycl. Chem. 14 (2008) 41-74.

[11] H.R. Jager, M.N. Taylor, T. Theodossy, C. Hopper, MR imaging-guided interstitial photodynamic laser therapy for advanced head and neck tumors, Am. J. Neuroradiol. 26 (2005) 1193-1200.

[12] R.K. Pandey, L.N. Goswami, Y. Chen, A. Gryshuk, J.R. Missert, A. Oseroff, T.J Dougherty, Tumor-imaging and photodynamic therapy, Laser Surg. Med. 38 (2006) 445-467.

[13] M.P.A. Williams, M. Ethirajan, K. Ohkubo, P. Chen, P. Pera, J. Morgan, W.H White, M. Shibata, S. Fukuzumi, K.M. Kadish, R.K. Pandey, Synthesis, photophysical, electrochemical, tumor-imaging, and phototherapeutic properties of purpurinimide-n-substituted cyanine dyes joined with variable lengths of linkers, Bioconj. Chem. 22 (2011) 2283-2295.

[14] A.N. Kozyrev, G. Zheng, C.F. Zhu, Synthesis of stable bacteriochlorophyll a derivatives as potential photosensitizers for photodynamic therapy, Tetrahedron Lett. 37 (1996) 6431-6434.

[15] A.F. Mironov, M.A. Grin, A.G. Tsiprovskij, D.V. Dzardanov, K.V. Golovin, A.V Feofanov, T.A. Karmakova, R.I. Jakubovskaja, Hydrazides in range of bacteriochlorophyll a eliciting photodynamic activity and method for their preparing. In RU Patent 2223274, OOO "FOTOGEM", 2004.

[16] M. Formica, V. Fusi, L. Giorgi, M. Micheloni, New fluorescent chemosensors for metal ions in solution, Coord. Chem. Rev. 256 (2012) 170-192.

[17] P.A. Panchenko, O.A. Fedorova, V. Fedorov, Fluorescent and colorimetric chemosensors for cations based on 1,8-naphthalimide derivatives: design principles and optical signalling mechanisms, Russ. Chem. Rev. 83 (2014) 155182.

[18] C. Coya, R. Blanco, R. Juárez, R. Gómez, R. Martínez, A. de Andrés, Á.L. Álvarez C. Zaldo, M.M. Ramos, A. de la Peña, C. Seoane, J.L. Segura, Synthesis and tunable emission of novel polyfluorene co-polymers with 1,8-naphthalimide pendant groups and application in a single layer-single component white emitting device, Eur. Polym. J. 46 (2010) 1778-1789.

[19] E. Martin, R. Weigand, A. Pardo, Solvent dependence of the inhibition of intramolecular charge-transfer in N-substituted 1,8-naphthalimide derivatives as dye lasers, J. Lumin. 68 (1996) 157-164.

[20] I. Grabchev, R. Betcheva, Copolymerization and photostabilization of methylmethacrylate with 1,8-naphthalimide fluorescent brighteners, J Photochem. Photobiol. A 142 (2001) 73-78.

[21] M. Sawa, T.-L. Hsu, T. Itoh, M. Sugiyama, S.R. Hanson, P.K. Vogt, C.-H. Wong Glycoproteomic probes for fluorescent imaging of fucosylated glycans in vivo, Proc. Natl. Acad. Sci. USA 103 (2006) 12371-12376.

[22] H.-H. Lin, Y.-C. Chan, J.-W. Chen, C.-C. Chang, Aggregation-induced emission enhancement characteristics of naphthalimide derivatives and their applications in cell imaging, J. Mater. Chem. 21 (2011) 3170-3177.

[23] A.F. Mironov, A.N. Kozyrev, A.S. Brandis, Sensitizers of second generation for photodynamic therapy of cancer based on chlorophyll and bacteriochlorophyll derivatives, Proc. SPIE 1992 (1922) 204-208.

[24] A.F. Mironov, M.A. Grin, A.G. Tsiprovskiy, V.V. Kachala, T.A. Karmakova, A.D. Plyutinskaya, R.I. Yakubovskaya, New bacteriochlorin derivatives with a fused N-aminoimide ring, J. Porphyrins Phthalocyanines 7 (2003) 725-730.

[25] D.F. Eaton, Reference materials for fluorescence measurement, Pure Appl Chem. 60 (1988) 1107-1114.

[26] S. Nad, M. Kumbhakar, H. Pal, Photophysical properties of coumarin-152 and coumarin-481 dyes: unusual behavior in nonpolar and in higher polarity solvents, J. Phys. Chem. A 107 (2003) 4808-4816.

[27] E. Lukovskaya, A. Bobylyova, Yu. Fedorov, A. Maksimov, A. Anisimov, O. Fedorova, G. Jonusauskas, F. Fages, Metal ion modulated torsion angle in a ditopic oligothiophene ligand: toward supramolecular control of $\pi$ conjugation, Chem. Phys. Chem. 11 (2010) 3152-3160.

[28] J.J.P. Stewart, Optimization of parameters for semiempirical methods V: modification of NDDO approximations and application to 70 elements, J. Mol. Model 13 (2007) 1173-1213.

[29] J.R. Lakowicz, Principles of Fluorescence Spectroscopy, Springer, New York, USA, 2006

[30] I. Grabchev, T. Konstantinova, Synthesis of some polymerisable 1,8naphthalimide derivatives for use as fluorescent brighteners, Dyes Pigm. 33 (1997) 197-203.

[31] I. Grabchev, Ch. Petkov, V. Bojinov, 1,8-naphthalimides as blue emitting fluorophores for polymer materials, Macromol. Mater. Eng. 287 (2002) 904908.

[32] D.W. Cho, M. Fujitsuka, U.C. Yoon, T. Majima, Intermolecular exciplex formation and photoinduced electron transfer of 1,8-naphthalimide dyads in methylated benzenes, J. Photochem. Photobiol. A 190 (2007) 101-109.

[33] P.A. Panchenko, Y.V. Fedorov, V.P. Perevalov, G. Jonusauskas, O.A. Fedorova, Cation-dependent fluorescent properties of naphthalimide derivatives with nbenzocrown ether fragment, J. Phys. Chem. A 114 (2010) 4118-4122.

[34] A.N. Sergeeva, P.A. Panchenko, Yu.V. Fedorov, O.A. Fedorova, Synthesis and sensor properties of crown-containing derivatives of 4-(1,5-diphenyl- $\Delta^{2}$ pyrazolin-3-yl)-1,8-naphthalimide, Prot. Metal. Phys. Chem. Surf. 48 (2012) 524-533. 